\title{
Instrumentation and Performance Analysis Plans for the HIFiRE Flight 2 Experiment
}

\author{
Mark Gruber, ${ }^{*}$ Todd Barhorst, ${ }^{\dagger}$ Kevin Jackson,${ }^{\ddagger}$ and Dean Eklund ${ }^{\S}$ \\ Propulsion Directorate, Air Force Research Laboratory, Wright-Patterson AFB, Ohio 45433 \\ Neal Hass ${ }^{* *}$ and Andrea M. Storch ${ }^{\dagger \dagger}$ \\ NASA Langley Research Center, Hampton, Virginia 23861 \\ Jiwen Liu ${ }^{\text {th }}$ \\ Taitech, Inc., Wright-Patterson, Ohio 45433
}

\begin{abstract}
Supersonic combustion performance of a bi-component gaseous hydrocarbon fuel mixture is one of the primary aspects under investigation in the HIFiRE Flight 2 experiment. In-flight instrumentation and post-test analyses will be two key elements used to determine the combustion performance. Pre-flight computational fluid dynamics (CFD) analyses provide valuable information that can be used to optimize the placement of a constrained set of wall pressure instrumentation in the experiment. The simulations also allow pre-flight assessments of performance sensitivities leading to estimates of overall uncertainty in the determination of combustion efficiency. Based on the pre-flight CFD results, 128 wall pressure sensors have been located throughout the isolator/combustor flowpath to minimize the error in determining the wall pressure force at Mach 8 flight conditions. Also, sensitivity analyses show that mass capture and combustor exit stream thrust are the two primary contributors to uncertainty in combustion efficiency.
\end{abstract}

\section{Nomenclature}

$\begin{array}{ll}A & =\text { cross-sectional area } \\ E & =\text { total energy flow } \\ F_{\text {Injection }} & =\text { injection force } \\ F_{\text {Pressure }} & =\text { wall pressure force } \\ F_{\text {Shear }} & =\text { shear force } \\ H & =\text { enthalpy } \\ I C & =\text { influence coefficient } \\ k & =\text { turbulent kinetic energy } \\ K E & =\text { kinetic energy flow } \\ m o m_{i} & =\text { momentum components } \\ M W & =\text { molecular weight } \\ P & =\text { pressure } \\ P r_{t} & =\text { turbulent Prandtl number } \\ Q & =\text { heat loss } \\ R S S & =\text { root-sum-square } \\ R_{u} & =\text { universal gas constant }\end{array}$

\footnotetext{
* Principal Aerospace Engineer, AFRL/RZAS. Associate Fellow.

${ }^{\dagger}$ Aerospace Engineer, AFRL/RZAS. Member.

* Senior Aerospace Engineer, AFRL/RZAS. Member.

${ }^{\S}$ Senior Aerospace Engineer, AFRL/RZAT. Senior Member.

** Senior Aerospace Engineer, Hypersonic Airbreathing Propulsion Branch. Member.

${ }^{\dagger}$ Aerospace Engineer, ATK/Hypersonic Airbreathing Propulsion Branch. Member.

\#esearch Engineer. Senior Member.
} 


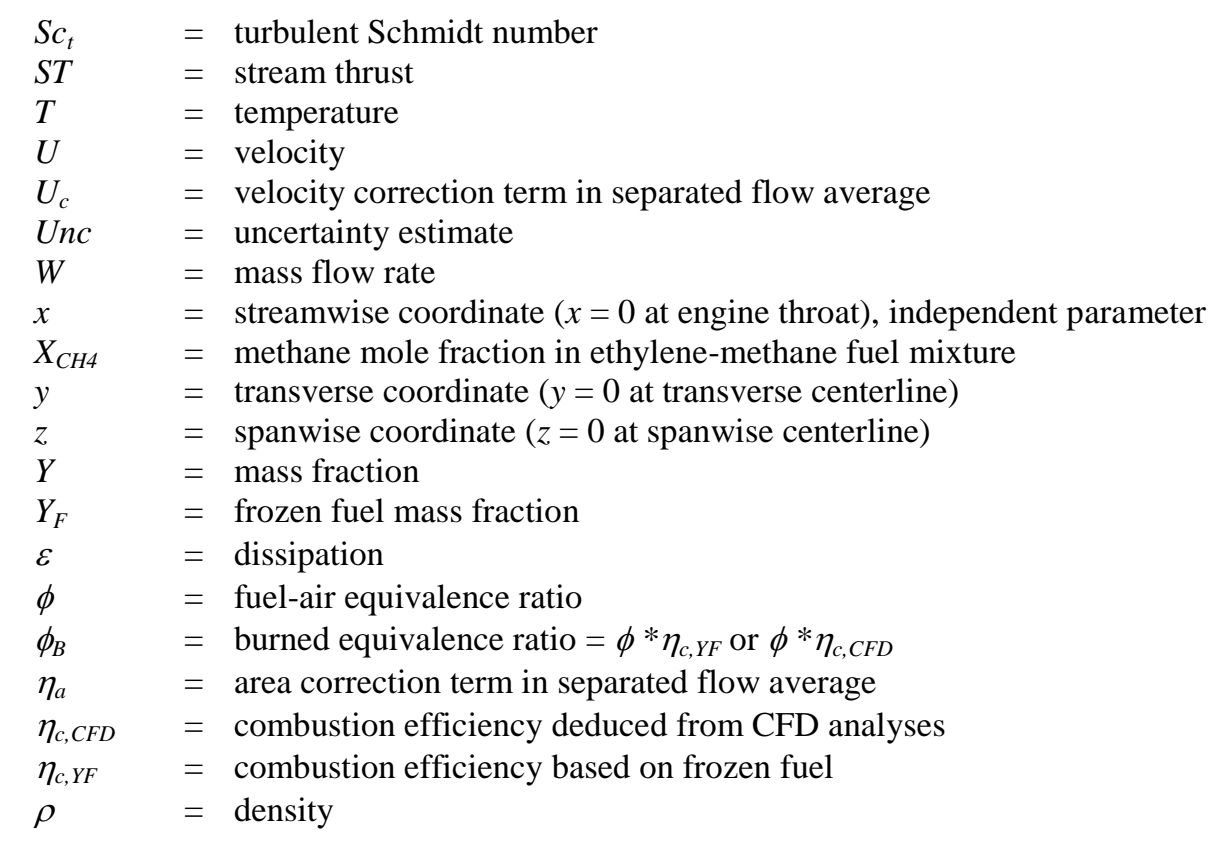

\section{Subscripts}

$A \quad=$ air stream

$E \quad=$ combustor exit

$F \quad=$ fuel stream

$i=$ species or component reference

ideal $=$ ideal condition

$I \quad=$ combustor inlet

ref $\quad=$ reference condition

$T=$ total or stagnation

\section{Introduction}

$\mathrm{T}$ he Hypersonic International Flight Research Experimentation (HIFiRE) Program is a collaborative international research effort that aims to study basic hypersonic phenomena through flight experimentation. A number of test flights are planned, with some designated to study the operation, performance, and stability characteristics of hydrocarbon-fueled supersonic combustors. Within this program, the HIFiRE Flight 2 (HF2) project team is led by the US Air Force Research Laboratory (AFRL) with NASA and the Australian Defence Science and Technology Organisation (DSTO) as vested partners. HF2 will explore Mach 8, hydrocarbon-fueled combustor performance and dual-to-scramjet mode transition in flight while also developing an alternative test technique for acquiring high enthalpy supersonic combustion flight test data.

The HIFiRE program follows the HyShot ${ }^{1}$ and HYCAUSE ${ }^{2}$ programs and aims to leverage much of the lowcost flight test technique developed therein. HF2 will be unique in its contribution to supersonic combustion research. This experiment will explore the use of a two-stage sounding rocket to achieve a variable Mach number trajectory that occurs at nearly constant dynamic pressure within the atmosphere. The Mach number and dynamic pressure ranges of interest for this flight experiment fall between Mach 5 and 9 and 47.9 to $143.6 \mathrm{kPa}$ (1000 to 3000 psf), respectively. The test article will be used to study dual-to-scramjet mode transition and supersonic combustion performance while remaining captive atop the actively-firing second stage booster. In this experiment, a bicomponent mixture of gaseous hydrocarbon fuels $(64 \%$ ethylene $+36 \%$ methane by volume) will be used to simulate a cracked liquid hydrocarbon fuel. ${ }^{3}$ Figure 1 shows a schematic of the full booster stack (including the launch and payload systems) and a cross-sectional view of the payload/shroud component. The shroud will be deployed prior to the scramjet experiment. The flowpath consists of a forebody/inlet section, an isolator/combustor section, and a bifurcated nozzle section. Additional information about the HF2 flight experiment can be found elsewhere. $^{4}$ 


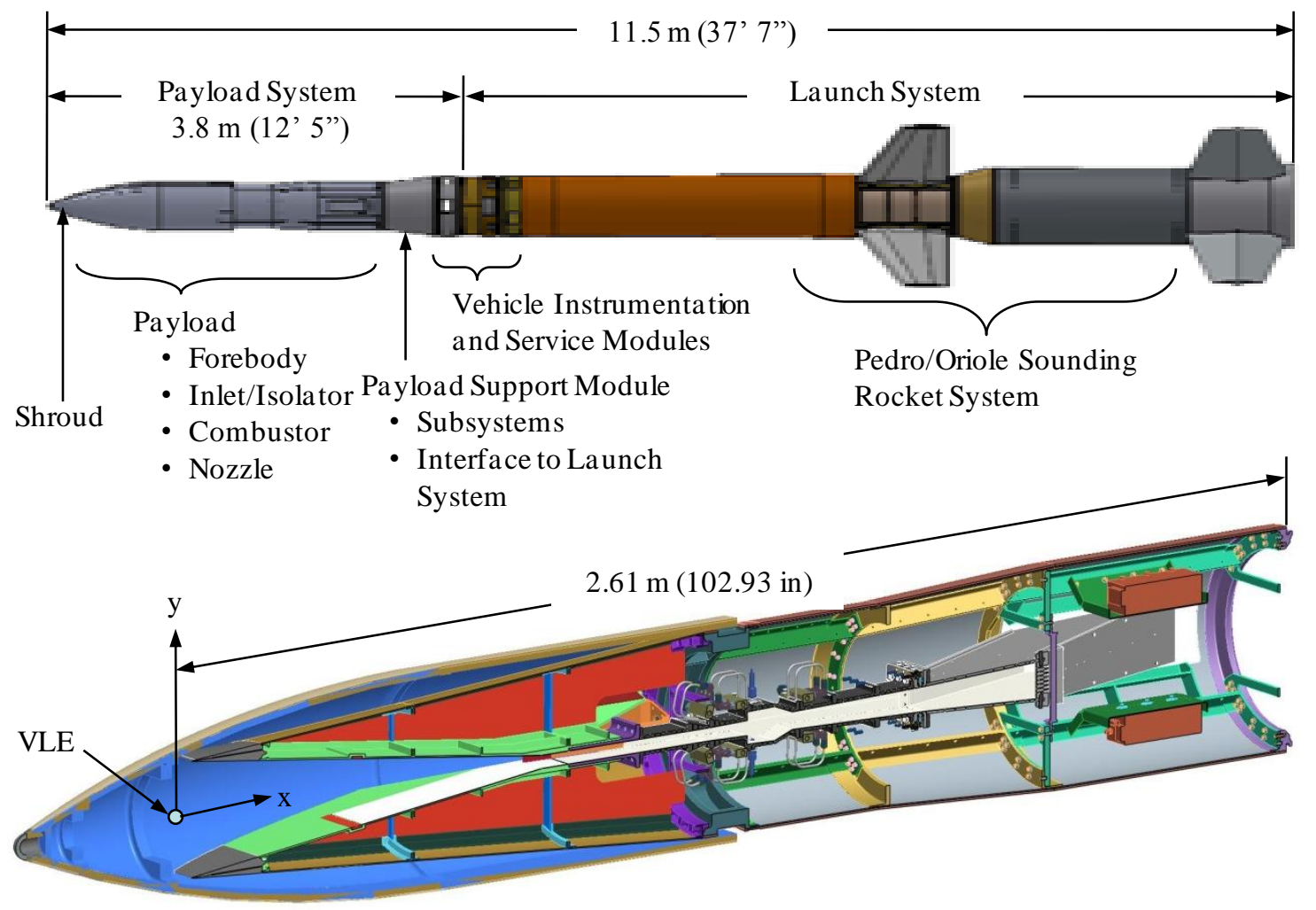

Figure 1. Schematics of the full booster stack and the payload/shroud component.

Several objectives are being carried in association with this flight experiment. These objectives, shown in Table 1, are classified as Primary (P) and Secondary (S). For the work reported in this paper, objective P2 is particularly relevant. A value for the burned equivalence ratio $\left(\phi_{B}=\phi^{*} \eta_{c}\right)$ greater than 0.7 has been targeted for Mach 8 conditions. Based on this objective, it is desirable to understand the anticipated uncertainty levels associated with the determination of combustion efficiency and equivalence ratio in order to assess the accuracy requirements for the various measurements that serve as input to the post-test analyses.

Computational fluid dynamics (CFD) tools have been used to develop the various components of the flowpath for this flight experiment including the forebody/inlet and the isolator/combustor. ${ }^{5,6}$ In the current work, the

Table 1. List of research objectives for HIFiRE Flight 2.

\begin{tabular}{l|l}
\hline \hline \multicolumn{2}{c}{ Primary Objectives } \\
\hline ID & Description \\
\hline P1 & Evaluate scramjet engine performance and operability through a dual-to-scram mode transition \\
\hline P2 & Achieve combustion performance of $\phi_{B} \geq 0.7$ at Mach 8 flight conditions using a hydrocarbon fuel \\
\hline P3 & $\begin{array}{l}\text { Demonstrate a scramjet flight test approach that provides a variable Mach number flight corridor at } \\
\text { nearly constant dynamic pressure }\end{array}$ \\
\hline \multicolumn{2}{c}{ Secondary Objectives } \\
\hline ID & Description \\
\hline S1 & Provide a test bed for diode laser-based instrumentation \\
\hline S2 & $\begin{array}{l}\text { Acquire high-fidelity core-flow measurements of combustion products (water) in a scramjet } \\
\text { operating environment up through Mach 8 flight conditions }\end{array}$ \\
\hline S3 & Evaluate the lean blow-out characteristics of a hydrocarbon fueled scramjet at or above Mach 8 \\
\hline S4 & Evaluate a gaseous fuel mixture as a surrogate for a cracked liquid hydrocarbon fuel \\
\hline S5 & Validate existing design tools for scramjet inlet, isolator, combustor, and nozzle components \\
\hline \hline
\end{tabular}


isolator/combustor CFD solutions are used to optimize the placement of wall pressure instrumentation in these sections of the flowpath in an attempt to minimize the errors associated with determining the wall pressure force during post-flight analyses. Sensitivity studies were conducted using the one-dimensional CFD data and the flight data reduction algorithm to assess the relative importance of various input parameters on the deduced combustion efficiency. This paper describes the analysis tools, the approach used to generate results, the specific analysis results, and the impact of these results on instrumentation layout and measurement uncertainty requirements.

\section{Isolator/Combustor Flowpath Description}

Figure 2 shows the isolator/combustor flowpath design that will be used in the HF2 flight experiment (flow direction is from left to right). This flowpath features a constant area isolator section, flush-wall fuel injection from primary (P1) and secondary (S1) injector sites, opposed cavity-based flameholders, and a constant divergence angle through the combustor (total included angle $=2.6^{\circ}$ ). The cross-sectional dimensions at the isolator entrance are 25.4$\mathrm{mm} \times 101.6-\mathrm{mm}$ (1-inch $\mathrm{x}$ 4-inches) and the overall length is just over 711-mm (28-inches). The design evolution of this flowpath is described in Ref. 6.

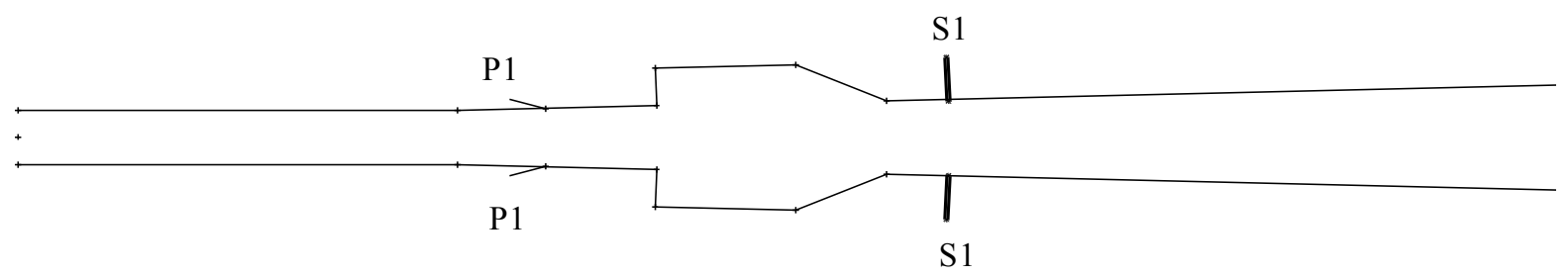

Figure 2. Isolator/combustor flowpath schematic.

\section{Performance Analysis Methodology}

The AFRL/RZAS in-house analysis code $\mathrm{QPERF}^{7}$ will be used to determine the combustion performance based on several in-flight measurements. This code solves the one-dimensional conservation equations shown in Eqs. 1-3 applied to the control volume shown in Figure 3 using measurements of fuel mass flow rate, heat loss, and exit pressure. In addition, exit area is assumed known (and at this time, uniform exit flow is assumed).

$$
\begin{gathered}
W_{E}=W_{A}+W_{F}=(\rho U A)_{E} \\
S T_{E}=(W U+P A)_{E} \\
W_{E} H_{T, E}=W_{E}\left(H+0.5 U^{2}\right)_{E}=W_{A}\left(H+0.5 U^{2}\right)_{I}+W_{F}\left(H+0.5 U^{2}\right)_{F}-Q
\end{gathered}
$$

GPS and inertial measurements on the booster/payload stack will be used to determine vehicle attitude, velocity, and altitude. These measurements will be used in post-test CFD simulations, along with in-flight measurements of Pitot pressure and wall pressure, to reconstruct inlet operation and performance and to determine $W_{A}$ and $U_{I}$. CFD solutions and

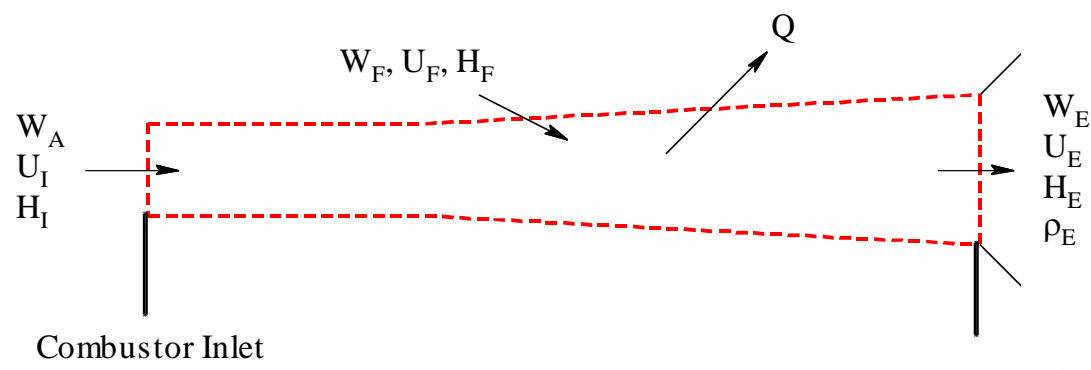

Combustor Exit

Figure 3. Control volume used for combustion efficiency analyses.

4

American Institute of Aeronautics and Astronautics 
booster measurements will also allow estimates of the air enthalpy. Fuel mass flow rate will be measured during the experiment and fuel enthalpy will be determined from the measured fuel properties using the REFPROP tool available from the National Institute of Standards and Technology (NIST). ${ }^{8}$ Fuel velocity will be determined by assuming sonic conditions at the fuel injector exit plane(s) for a known fuel mixture and using measured fuel manifold properties. Heat loss from the control volume will be estimated from measurements of wall temperatures and heat fluxes throughout the flowpath.

Because the second-stage booster will be firing continuously during the flight experiment, any thrust generated by the combustor will be impossible to discern from GPS or inertial measurements with sufficient accuracy for use in a post-test performance analysis. However the combustor exit stream thrust can be determined as follows:

$$
S T_{E}=S T_{I}+F_{\text {Pressure }}+F_{\text {Injection }}-F_{\text {Shear }}
$$

In this expression, the combustor inlet stream thrust $\left(S T_{I}\right)$, the wall pressure force $\left(F_{\text {Pressure }}\right)$, the force exerted by fuel injection $\left(F_{\text {Injection }}\right)$, and the shear force $\left(F_{\text {Shear }}\right)$ must each be determined.

The combustor inlet stream thrust can be computed from the definition of stream thrust as follows:

$$
S T_{I}=(W U+P A)_{I}=W_{A} U_{I}+(P A)_{I}
$$

Throat static pressure $\left(P_{I}\right)$ will be measured and throat cross-sectional area $\left(A_{I}\right)$ will be known.

The wall pressure force will be determined during the experiment by measuring wall pressure from various locations throughout the isolator/combustor flowpath. These measurements will also be used with post-test CFD analyses for verification. The force due to fuel injection will be determined using computational simulations along with in-flight measurements of fuel flow rate and fuel pressure. The shear force will not be measured and is therefore the largest unknown in Eq. 4. Computational simulations and historical databases will be used to provide guidance on the local and/or global shear stress values for use in determining the shear force.

There are four remaining unknowns in Eqs. 1-3: combustor exit density $\left(\rho_{E}\right)$, combustor exit enthalpy $\left(H_{E}\right)$, combustor exit velocity $\left(U_{E}\right)$, and the mass fraction of frozen or unburned fuel in the combustor exhaust $\left(Y_{F}\right)$. Equation 2 yields the following relationship for $U_{E}$ :

$$
U_{E}=\left(\frac{S T-P A}{W}\right)_{E}
$$

This expression is substituted into Eqs. 1 and 3 to yield $\rho_{E}$ and $H_{E}$, respectively. A value for $Y_{F}$ is initially selected and input into a chemical equilibrium package using the known combustor exit pressure and total enthalpy (Eq. 3) to yield the static temperature and molecular weight of the combustion products. Then the combustor exit density is found from the equation of state (Eq. 7).

$$
\rho_{E}=\frac{M W}{R_{u}}\left(\frac{P}{T}\right)_{E}
$$

A Newton's iteration is used to vary $Y_{F}$ until the density from Eq. 7 matches that determined from Eq. 1 to within a prescribed convergence criterion. Once $Y_{F}$ is known, the equilibrium code is used to compute the exit total temperature. The ideal total temperature is obtained by repeating the equilibrium calculation setting $Y_{F}$ to $1.0 \times 10-6$. The total temperature at the combustor inlet is obtained from the CFD solutions. Finally, combustion efficiency is computed using the mass fraction of frozen fuel (Eq. 8).

$$
\eta_{c, Y F}=1-Y_{F} \text { when } \phi \leq 1 \text { and } \eta_{c, Y F}=\left(1-Y_{F}\right) \phi \text { when } \phi>1
$$




\section{Computational Resources}

Three-dimensional simulations were performed using the CFD++ code, a general-purpose CFD tool developed by Metacomp Technologies. ${ }^{9}$ CFD++ uses a finite-volume numerical framework, with multi-dimensional TVD schemes and Riemann solvers for accurate representation of supersonic flows. Multi-grid acceleration is available to provide a fast and accurate solution methodology for both steady and unsteady flows. A variety of one-, two-, and three-equation turbulence models are available for RANS calculations, along with large eddy simulation (LES) and hybrid RANS/LES options. Chemically reacting flows can be modeled with a general finite-rate kinetics model or a user specified function for chemistry. The code supports both structured (quadrilateral and hexahedral) and unstructured (triangle, prism, and tetrahedral) grids. MPI is used to take advantage of modern parallel-processing computers.

CFD++ has several types of Riemann solvers; the HLLC Riemann solver with Minmod flux limiting was used in the current simulations. Unless otherwise specified, turbulence was modeled with the two-equation cubic $k-\varepsilon$ model. This model has non-linear terms that account for normal-stress anisotropy, swirl, and streamline curvature. At solid surfaces, an advanced two-layer wall function with the blended mode of equilibrium and non-equilibrium was employed to reduce grid requirements. The turbulent Schmidt $\left(S c_{t}\right)$ and Prandtl $\left(P r_{t}\right)$ numbers control the modeled turbulent transport of mass and energy, respectively, and they were set to constant values. The value for $S c_{t}$ was calibrated to be 0.6 based on the comparison with experimental data and the value for $P r_{t}$ was selected to be 0.9. Chemical kinetics were modeled using the reduced kinetic mechanism generated by the Princeton University. This mechanism consists of 22 species and it was developed based on the detailed mechanism of Qin, et al. ${ }^{10}$

Three-dimensional CFD data were reduced to equivalent one-dimensional results using the separated-flow averaging technique. This method uses two distortion terms and results in the preservation of mass, momentum, and energy flows along with the pressure force and kinetic energy flow while introducing little artificial entropy gain. In this method, the projected areas $\left(A_{i}\right)$, mass flow $(W)$, momentum flows $\left(m^{\prime} m_{i}\right)$, total energy flow $(E)$, pressure force in each direction $\left(P A_{i}\right)$, and kinetic energy flow $(K E)$ are determined by integrating the CFD solution. Species mass fractions are then determined from the ratio of each species flow to the total mass flow. The static pressure is found using

$$
P=\frac{P \vec{A} \cdot \vec{A}}{\vec{A} \cdot \vec{A}}
$$

The static enthalpy is determined from

$$
H=\frac{E-K E}{W} .
$$

The density, temperature, and entropy are then determined using the equation of state that was used in the CFD solver. Next, the velocity components are found using

$$
U_{i}=\frac{\mathrm{mom}_{i}-P A_{i}}{W} \text { for } i=x, y, z .
$$

Finally, the extra distortion terms are found using

$$
\eta_{a}=\frac{W}{\rho(\vec{U} \cdot \vec{A})}, \quad U_{c}=\frac{2 K E}{W(\vec{U} \cdot \vec{U})} .
$$

Typically, the distortion terms remain near unity for non-separated flows. In these cases, the separated flow averaging technique yields values that are very close to other averaging procedures. For separated flows like those encountered in shock trains and over cavity flameholders, the value of $\eta_{a}$ decreases to mimic the actual flow area.

Burned equivalence ratio was computed at the combustor exit station using $\phi_{B}=\phi^{*} \eta_{c, C F D}$. In this expression, the combustion efficiency at the combustor exit is computed based on static enthalpy change using 


$$
\eta_{c, C F D}=\frac{H\left(T_{r e f}, Y_{i}\right)-H\left(T_{r e f}, Y_{i, r e f}\right)}{H\left(T_{r e f}, Y_{i, \text { ideal }}\right)-H\left(T_{r e f}, Y_{i, r e f}\right)},
$$

where the reference condition is at the isolator entrance and the ideal condition is determined from an equilibrium calculation using the static pressure and static enthalpy at the combustor exit station.

\section{Analysis Approach}

As noted above, combustor performance analysis requires an estimate of the combustor exit stream thrust using Eq. 4. The term of largest magnitude in this expression will be the wall pressure force. Isolator/combustor CFD solutions provide a useful database for optimizing the placement of a constrained set of pressure instrumentation to minimize the errors in determining the wall pressure force. Additionally, CFD solutions provide 1D parameters for input into the QPERF performance code. This allows direct comparison between combustion efficiency values determined by both analysis approaches. Further, sensitivity and uncertainty analyses can be performed to identify parameters having large influences on combustor performance. Attempts can then be made to minimize the uncertainties associated with these key parameters.

\section{A. Specification of Wall Pressure Instrumentation}

Pre-test CFD results were used to guide the placement of pressure instrumentation within the flight vehicle. The pressure force was computed for the entire flowpath on a section-by-section basis by integrating the pressure data from the full 3D CFD results. Six sections were defined for this analysis: isolator, primary fuel injection, cavity step, cavity floor, cavity ramp, and combustor. Figure 4 shows a sample Mach 8 combustor CFD solution where the various flowpath sections are designated. Table 2 contains the section-by-section pressure force data obtained from the CFD solutions at Mach 6, 7, and 8 flight conditions along the nominal trajectory. It should be noted that, because the isolator section is constant-area, there is no force contribution.

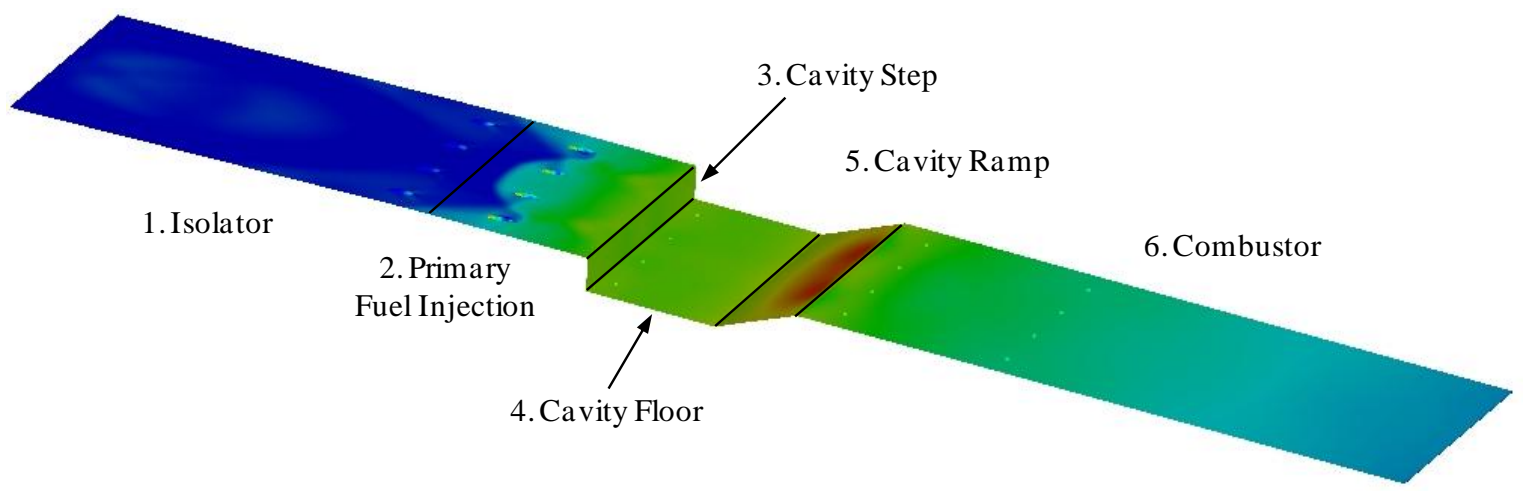

Figure 4. CFD pressure distribution from Mach 8 flight conditions.

The CFD solution was then discretized using distributions of pressure taps and the pressure force was recomputed based on this subset of information. The goal of this effort was to adjust the pressure tap locations in order to minimize the difference between the pressure forces computed from the full CFD solution and the

Table 2. Pressure force results obtained by integrating the full 3D CFD solutions.

\begin{tabular}{c|c|c|c|c|c|c|c}
\hline \hline \multirow{2}{*}{$\mathbf{M}$} & \multicolumn{7}{|c}{ Pressure Force (N) } \\
\cline { 2 - 8 } & Isolator & $\begin{array}{c}\text { Primary } \\
\text { Fuel } \\
\text { Injection }\end{array}$ & Cavity Step & $\begin{array}{c}\text { Cavity } \\
\text { Floor }\end{array}$ & $\begin{array}{c}\text { Cavity } \\
\text { Ramp }\end{array}$ & Combustor & Total \\
\hline 6 & 0.0 & 330.13 & 2855.43 & 249.53 & -2831.20 & 578.43 & 1182.33 \\
\hline 7 & 0.0 & 240.86 & 2254.13 & 196.00 & -2365.54 & 480.24 & 805.68 \\
\hline 8 & 0.0 & 110.30 & 1543.11 & 133.66 & -1752.56 & 397.70 & 432.02 \\
\hline \hline
\end{tabular}


discretized dataset. For this analysis, a Matlabbased program was used to extract the pressure data from the $3 \mathrm{D}$ CFD solution corresponding to the desired pressure tap locations. A root-mean-squared algorithm was used to find the closest points in the CFD solution to the desired pressure tap locations. Pressure data were extracted from the CFD solution at these locations and were input into a forwardmarching algorithm to determine the wall pressure force. This algorithm marched downstream from the isolator entrance through the various sections shown in Figure 4. When the code encountered a pressure tap within a given section of the flowpath, a check was performed to determine if other pressure taps were positioned at that same axial station (in this flowpath, instruments are arranged on all four walls). If there were other taps at a given axial location, then the numerical average of all taps at that axial station was computed.

A generic flowpath section is shown schematically in Figure 5. At station 1, three pressure taps are used in the average to generate $P_{l}$. In this case, $P_{l}$ is applied to the area between stations 0 and 1 such that $F_{01}=P_{1} \times\left(A_{l}-A_{0}\right)$. At station 2, a single pressure tap is used to define $P_{2}$. Now, the average of $P_{1}$ and $P_{2}$ is applied to the area between stations 1 and 2 such that $F_{12}=0.5 \times\left(P_{1}+P_{2}\right) \times\left(A_{2}-A_{1}\right)$. This approach continues in the axial direction until the final station of this flowpath section is reached (in this example, station $\mathrm{N}$ ). Here, three taps are averaged to determine $P_{N \text { - }}$ $l$ and this pressure is applied to the area between stations $\mathrm{N}$ and $\mathrm{N}-1$ such that $F_{N-1 N}=P_{N-1} \times\left(A_{N}-A_{N-1}\right)$. The sum of the discrete forces then represents the pressure force on this section of the flowpath. To verify this algorithm, a uniform pressure $(P)$ was applied to the isolator/combustor flowpath and the resultant pressure force was computed. In this case, the code output was compared with the value $P \times\left(A_{E}-A_{I}\right)$ to determine validity.

Results from these analyses were examined in three ways. First, a section-by-section comparison between the 3D CFD output and the discretized analysis was done to examine how effectively a given distribution of pressure taps reproduced the wall pressure force determined from the CFD simulation. Second, the total wall pressure forces (i.e., sum from all sections) for the full and discretized solutions were compared. This was an interesting comparison in that excellent results in total could be obtained if errors in various sections were offsetting. Finally, the root-sumsquare of the section-by-section differences was computed. These results represented an overall "wellness" assessment that did not allow offsetting errors within sections to artificially bias interpretation.

\section{B. Performance Sensitivity Study}

One-dimensional results obtained from the pre-test CFD solutions were used with the QPERF code to determine the uncertainty associated with the combustion efficiency measurement. Table 3 lists the parameters used in QPERF to determine combustion efficiency and their nominal values obtained from Mach 6, 7, and 8 combustor simulations. Each of the input parameters was perturbed as shown in Table 3, holding the other values constant, and QPERF was re-executed to determine the influence of the perturbation on the deduced combustion efficiency. An influence coefficient was determined for each parameter $\left(x_{i}\right)$ based on the expression shown in Eq. 14.

$$
I C_{i}=\frac{\partial \eta_{c}}{\partial x_{i}} \approx \frac{\left[\frac{\eta_{c}\left(x_{i}\right)-\eta_{c}\left(x_{i}+\Delta x_{i}\right)}{\eta_{c}\left(x_{i}\right)}\right]}{\left(\frac{x_{i}-\Delta x_{i}}{x_{i}}\right)}
$$

Once obtained, these influence coefficients may be combined with the respective uncertainty estimates ( $U n c_{i}$ ) for each parameter to determine a total uncertainty estimate on combustion efficiency using Eq. 15 . $^{11}$

$$
U n c=\sqrt{\sum\left(I C_{i}^{*} U n c_{i}\right)^{2}}
$$


Table 3. One-dimensional CFD results from Mach 6, 7, and 8 combustor simulations used as input to QPERF.

\begin{tabular}{l|c|c|c|c}
\hline \hline Parameter & Mach 6 $(\phi=1.0)$ & Mach 7 $(\phi=1.0)$ & Mach 8 $(\phi=1.0)$ & Perturbed Values \\
\hline Primary Injection $(\%)$ & 70 & 100 & 100 & - \\
\hline$W_{A}, \mathrm{~kg} / \mathrm{s}(\mathrm{lbm} / \mathrm{s})$ & $2.699(5.950)$ & $2.288(5.044)$ & $1.906(4.202)$ & $\pm 1 \%$ \\
\hline$W_{F}, \mathrm{~kg} / \mathrm{s}(\mathrm{lbm} / \mathrm{s})$ & $0.175(0.387)$ & $0.149(0.328)$ & $0.124(0.273)$ & $\pm 1 \%$ \\
\hline$T_{T A}, \mathrm{~K}(\mathrm{R})$ & $1560(2808)$ & $2008(3614)$ & $2531(4556)$ & $\pm 1 \%$ \\
\hline$H_{F}, \mathrm{~kJ} / \mathrm{kg}(\mathrm{BTU} / \mathrm{lbm})$ & $287.4(123.5)$ & $287.4(123.5)$ & $287.4(123.5)$ & $\pm 1 \%$ \\
\hline$X_{C H 4}$ & 0.36 & 0.36 & 0.36 & $0.40,0.32$ \\
\hline$Q, \mathrm{~kW}(\mathrm{BTU} / \mathrm{s})$ & $923(875)$ & $1062(1007)$ & $1151(1091)$ & $\pm 1 \%$ \\
\hline$S T_{E}, \mathrm{~N}(\mathrm{lbf})$ & $5038(1133)$ & $4705(1058)$ & $4212(946.8)$ & $\pm 1 \%$ \\
\hline$P_{E}, \mathrm{kPa}(\mathrm{psia})$ & $307.8(44.65)$ & $241.3(34.99)$ & $202.8(29.41)$ & $\pm 1 \%$ \\
\hline Width $_{E}, \mathrm{~mm}$ (inches) & $101.6(4.000)$ & $101.6(4.000)$ & $101.6(4.000)$ & $\pm 1 \%$ \\
\hline Height $_{E}, \mathrm{~mm}$ (inches) & $48.46(1.908)$ & $48.46(1.908)$ & $48.46(1.908)$ & $\pm 1 \%$ \\
\hline$\eta_{c, C F D}$ & 0.82 & 0.89 & 0.96 & - \\
\hline
\end{tabular}

\section{Results}

This section will present the results from the various analyses described above. Wall pressure instrumentation results will be discussed first, including descriptions of two pressure tap distributions and how well these measurement locations reproduce the integrated wall pressure results from the full 3D CFD solutions at Mach 6, 7, and 8 flight conditions. Following these, combustion efficiency and sensitivity analysis results will be shown for the three flight conditions. These results will conclude with estimates of overall uncertainty in combustion efficiency assuming specific parameter-level uncertainties. Recommendations for possible improvements in certain parameterlevel uncertainties will be made.

\section{A. Wall Pressure Instrumentation}

Figure 6 presents the baseline pressure tap distribution. In this case, 164 pressure taps were located throughout the flowpath as shown by the black dots. The locations of these taps were selected prior to the completion of any CFD analyses on this flowpath. Wall pressure data from the Mach 8 CFD simulation are also included in Figure 6. The upper image shows the entire isolator/combustor (with flow from left to right) while the lower image focuses on the cavity region (flow is again left to right but the viewing angle and the color scale are different than the upper image). Body and cowl walls were instrumented identically along with a symmetric array of taps placed on each sidewall in the primary fuel injection region. Despite the fact that the constant-area isolator does not contribute to the total pressure force, pressure measurements were prescribed in this region to provide assessments of shock train position during the mode transition experiment. Taps were placed primarily along the body and cowl centerlines, although off-centerline taps were specified at five axial locations including the cavity step. The cavity ramp was only instrumented on the spanwise

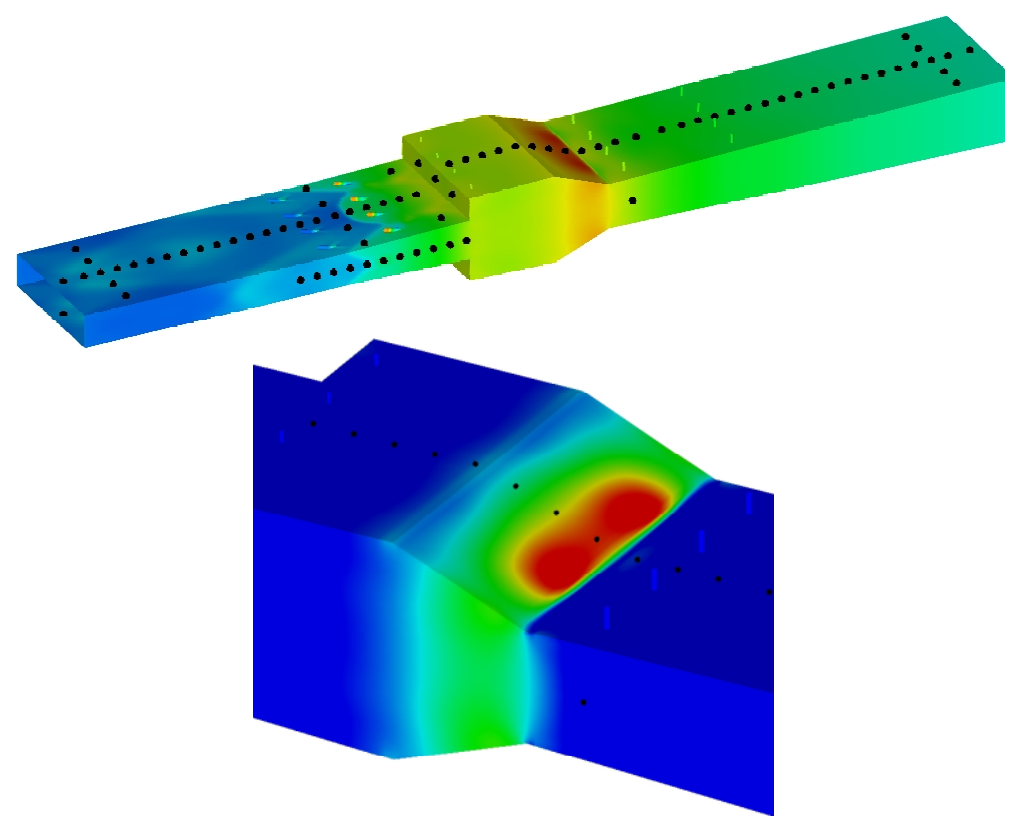

Figure 6. Baseline pressure tap distribution shown along with Mach 8 wall pressure results. 
centerline. The bar graph in Figure 7 shows the differences between the discretized pressure distribution for Mach 6, 7, and 8 flight conditions and the full CFD results (see Table 2). It is immediately obvious that the force on the cavity ramp is not well reproduced by the baseline pressure tap distribution at the Mach 6 condition $\quad(8.75 \%$ different than predicted) and is the dominant source of error for all flight conditions. The pressure taps yield excellent agreement throughout the rest of the flowpath. Figure 6 reveals a highly three-dimensional wall pressure field near the primary fuel injectors and on the cavity ramp. Downstream of the cavity ramp, there is very little spanwise pressure variation within the combustor. Refinements in these areas are expected to improve the overall comparison.

In an attempt to improve the resolution of the cavity ramp force, and improve both total and RSS errors, several revised pressure tap distributions were studied. Figure 8 shows the results from Revision 25, where the total number of pressure taps was reduced (to 128) and adjustments were made to the distribution of taps throughout the flowpath. Changes included placing additional taps on the cavity ramp, removing every other pressure tap on the cowl wall, and staggering the body and cowl taps at off-centerline locations. Also, the spanwise row near the combustor exit was eliminated and the spanwise row in the fuel injection region near the cavity step was moved slightly upstream to better capture the three-dimensional pressure distribution in that area. The number of taps was reduced to be consistent with a manageable set of 32-channel Esterline pressure scanners (ESP-32HD). These pressure-scanning modules were selected as part of the baseline instrumentations suite for HF2.

For this distribution of pressure taps, substantial improvements were made to both the total and the RSS errors, as shown in Figure 9. For the Mach 8 condition, the total difference between the full CFD solution and the discretized data was less than $1 \mathrm{~N}$ and the RSS difference was less than $4 \mathrm{~N}$. Compromises were made to the results at the Mach 6 and 7 conditions since a single pressure tap distribution could not sufficiently reproduce the cavity ramp force for all conditions. For the Mach 6 and 7 conditions, the combustor operates either in dualmode or in a transitional mode resulting in significantly different three-dimensional

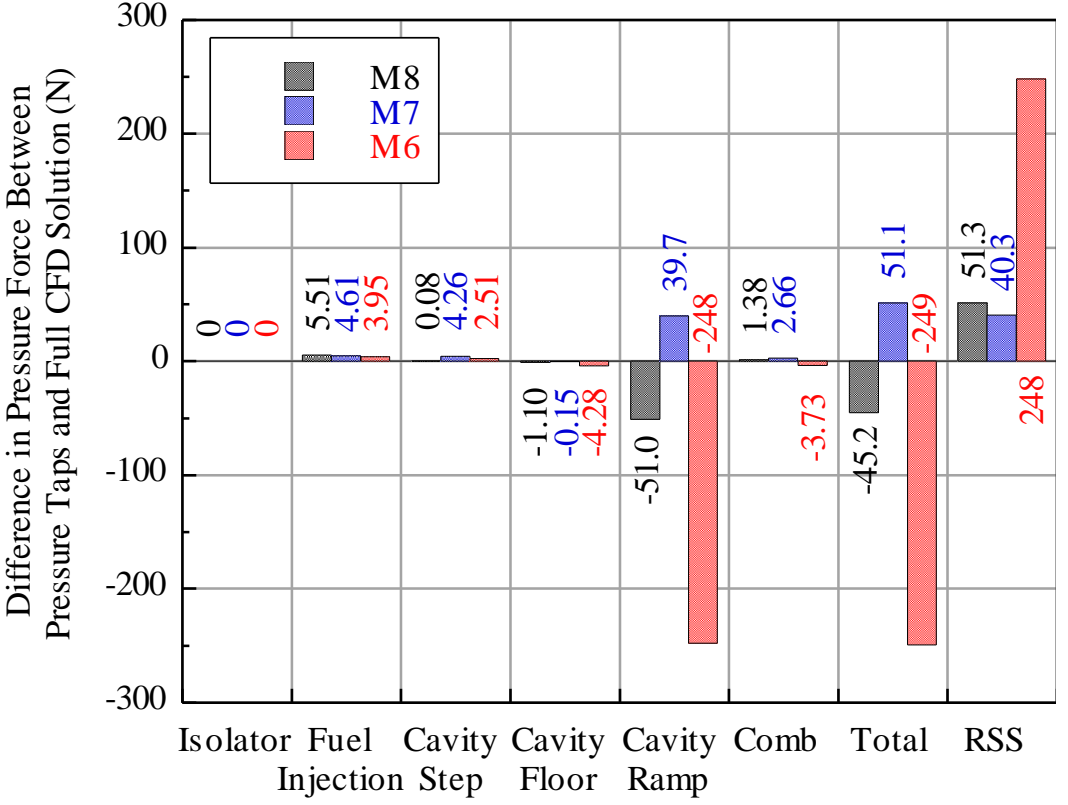

Figure 7. Comparison of pressure force characteristics between the full CFD and baseline pressure tap distribution.

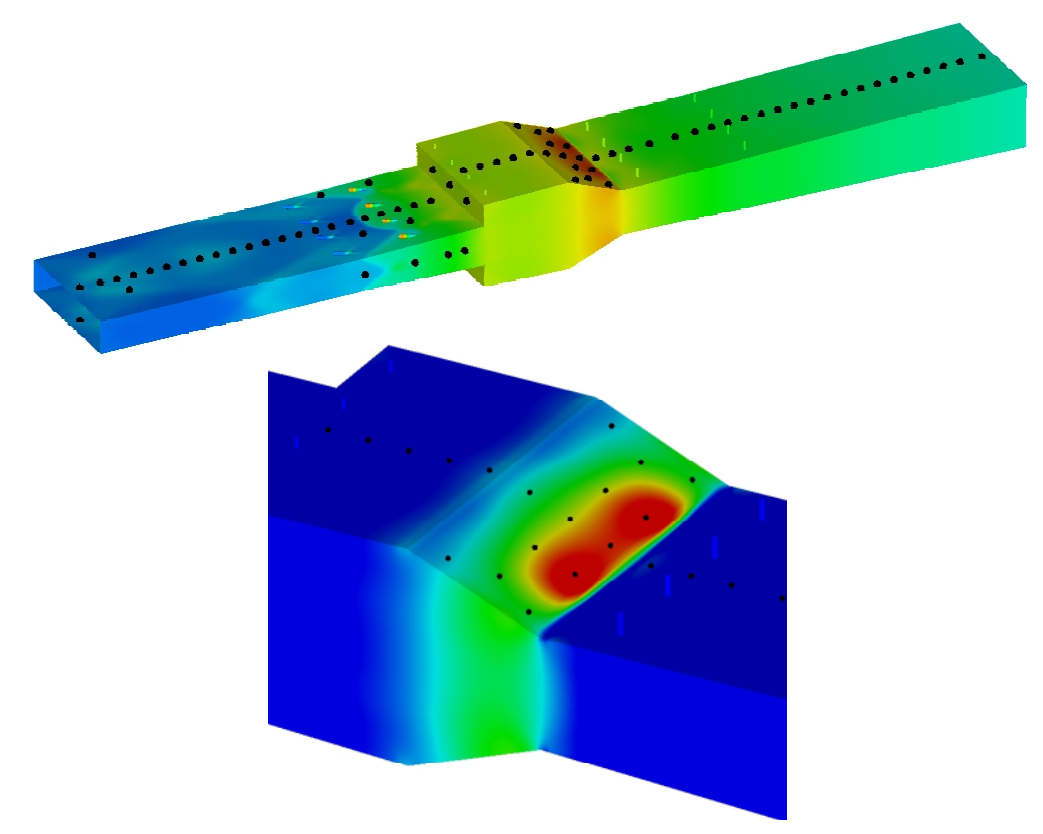

Figure 8. Modified pressure tap distribution shown along with Mach 8 wall pressure results. 
distributions on the cavity ramp. Because the flight experiment objectives do not include performance goals associated with these flight conditions, the pressure tap distribution was optimized for the Mach 8 condition. This approach will minimize the overall uncertainty in combustor exit stream thrust (Eq. 5), which will reduce the overall uncertainty in deduced combustion efficiency (as will be discussed in the following sections). Nevertheless, substantial improvements were observed for all flight conditions using this pressure tap distribution. Errors in total pressure force between the discretized data and the full CFD solution for Mach 6, 7, and 8 cases are $3.6 \%, 1.3 \%$, and $0.06 \%$, respectively.

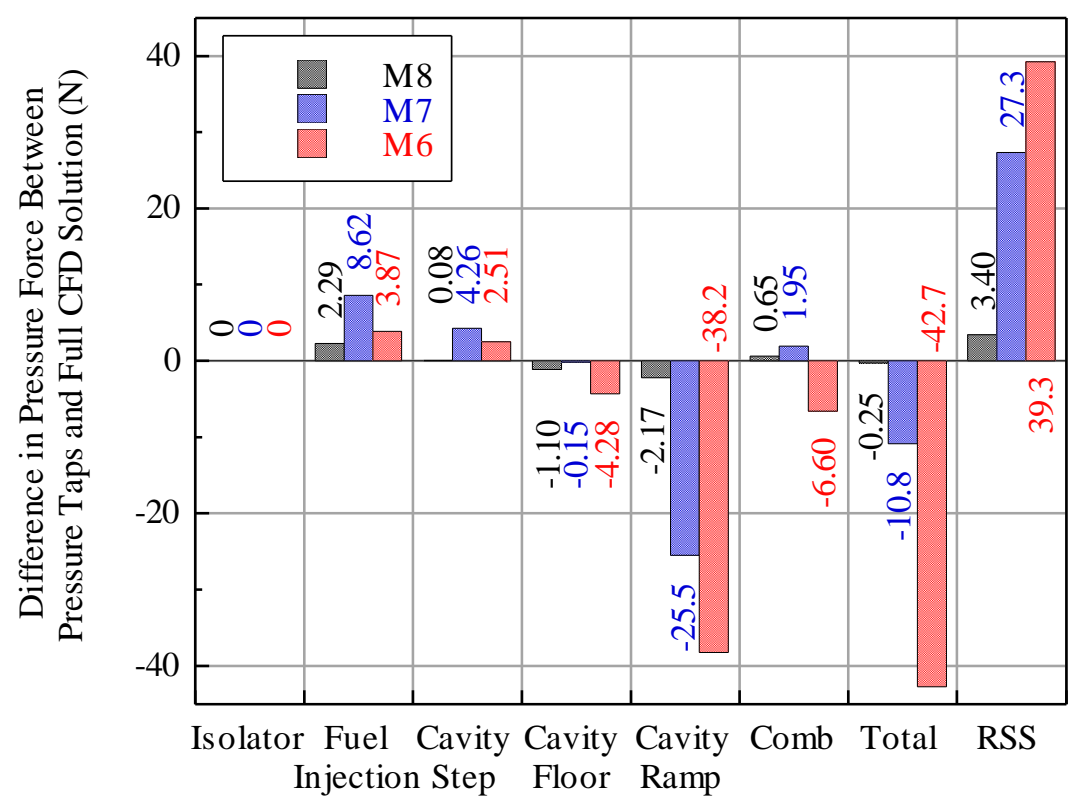

Figure 9. Comparison of pressure force characteristics between the full CFD solution and the modified pressure tap distribution.

\section{B. Combustion Efficiency}

Figure 10 compares the combustion efficiency results from CFD (Table 3) and QPERF analyses for Mach 6, 7, and 8 flight conditions. It should be noted that for the Mach 8 case, the nominal air mass flow rate listed in the table did not result in a converged QPERF solution. In order to obtain convergence, the air mass flow rate for this case had to be increased by at least $0.25 \%$ (minimum air flow rate required for complete combustion). For the purposes of this analysis, the nominal value for air mass flow rate for the Mach 8 case was increased by $1 \%$. This suggests that the combustion performance in the Mach 8 case is very nearly $100 \%$ and small changes in important parameters (like air mass flow rate and combustor exit stream thrust) may lead to unphysical analysis results. The Mach 6 and 7 cases show very good agreement between the combustion efficiencies derived from CFD and QPERF. In these cases, combustion efficiency values are predicted to be near $80 \%$ and $90 \%$, respectively. The close comparison between these analysis results gives good confidence that the QPERF code will produce reliable values for combustion efficiency given the correct $1 \mathrm{D}$ input values.

\section{Sensitivity Analyses}

The sensitivity analyses reveal the primary parameters that have the strongest influence on the determination of combustion efficiency. Figure 11 through

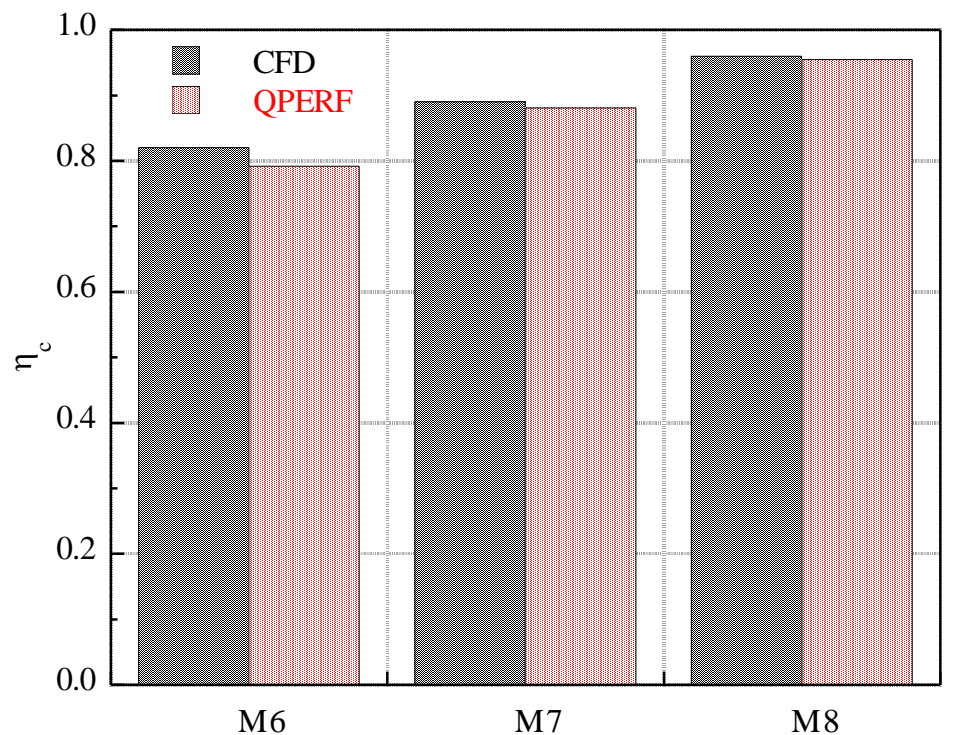

Note that Mach 8 QPERF results used ${ }_{A}$ of $1 \%$ higher than nominal Minimum value of $W_{A}$ for $\eta_{c}=1$ is $0.25 \%$ higher than nominal.

Figure 10. Combustion efficiency results.

American Institute of Aeronautics and Astronautics 
Figure 13 show the results of the sensitivity study for geometric, air/fuel, and performance parameters. Each bar graph plots the value of the influence coefficient (defined in Eq. 14) for each parameter. The superscript on the various parameters indicates which direction it was perturbed. Generally, the influence coefficient magnitudes are independent of perturbation direction (i.e., up or down from nominal), although there are certain parameters where this is not the case. Specifically, air and fuel mass flow rates exhibit different influence coefficient magnitudes depending on the perturbation direction. This is caused when the perturbed value of air or fuel mass flow rate results in $\phi>1$. When this happens, the combustion efficiency definition changes (as shown in Eq. 8) because the least available reactant changes from fuel (for $\phi<1$ ) to oxygen (for $\phi>1$ ). This effect is most pronounced for the Mach 6 and 7 cases.

Many parameters have very small influences on combustion efficiency (e.g., fuel enthalpy $\left(H_{F}\right)$, combustor heat loss $(Q)$, and fuel composition $\left.\left(X_{C H 4}\right)\right)$ while others have very significant influences (e.g., air mass flow rate $\left(W_{A}\right)$ and combustor exit stream thrust $\left(S T_{E}\right)$ ). It is also noted that flight conditions affect the magnitudes of the influence coefficients: values decrease monotonically from Mach 8 to Mach 6 conditions for all parameters. At the Mach 8 condition, QPERF did not converge when the air mass flow rate was reduced by $1 \%$ (see Figure 12). Recall that the nominal air mass flow rate for this condition shown in Table 3 had to be arbitrarily increased by at least $0.25 \%$ in order to obtain convergence. Similarly, QPERF did not converge when the combustor exit stream thrust was increased by $1 \%$ (see Figure 13). Together, these observations show how sensitive the determination of combustion efficiency is to these two parameters. They also indicate that the Mach 8 combustion efficiency is nearly $100 \%$ such that slight reductions in air mass flow rate or increases in exit stream thrust result in unphysical situations.

The influence coefficients can be combined with estimates of parameter-level uncertainties to obtain an estimate of the total uncertainty for combustion efficiency using Eq. 15. To be conservative in this assessment, the larger value of each parameter's influence

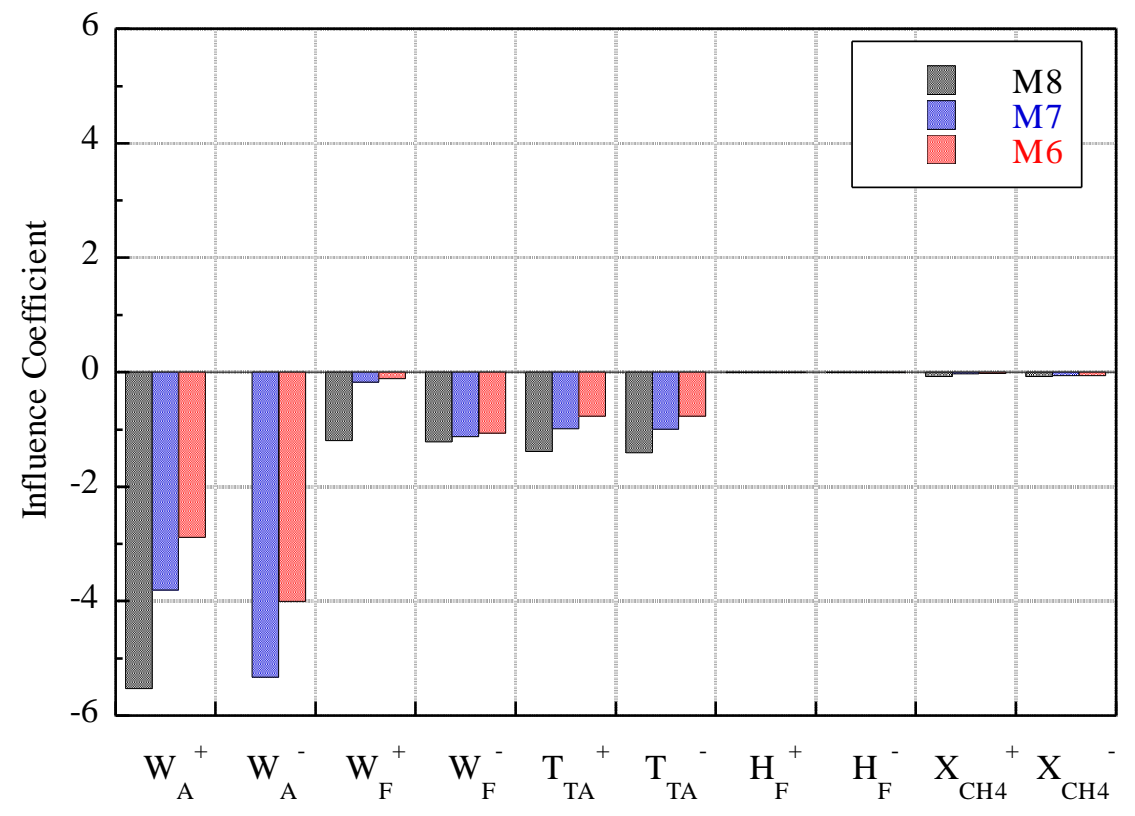

Figure 12. Influence coefficients for air and fuel parameters.

12

American Institute of Aeronautics and Astronautics 
coefficient was used in this analysis. For example, the influence coefficients for air mass flow rate at Mach 7 flight conditions have the following values: $W_{A}{ }^{+}=-3.81$ and $W_{A}{ }^{-}=-$ 5.33. The $W_{A}^{-}$value was used for in the uncertainty analysis. Where possible, nominal values were selected for parameter-level uncertainties based on design requirements (geometric parameters and fuel mass flow rate) or specific instrumentation (combustor exit pressure). Other uncertainty values are based on initial engineering estimates (heat loss, fuel composition, fuel enthalpy, and air properties). Finally, the estimate for uncertainty of combustor exit stream thrust is

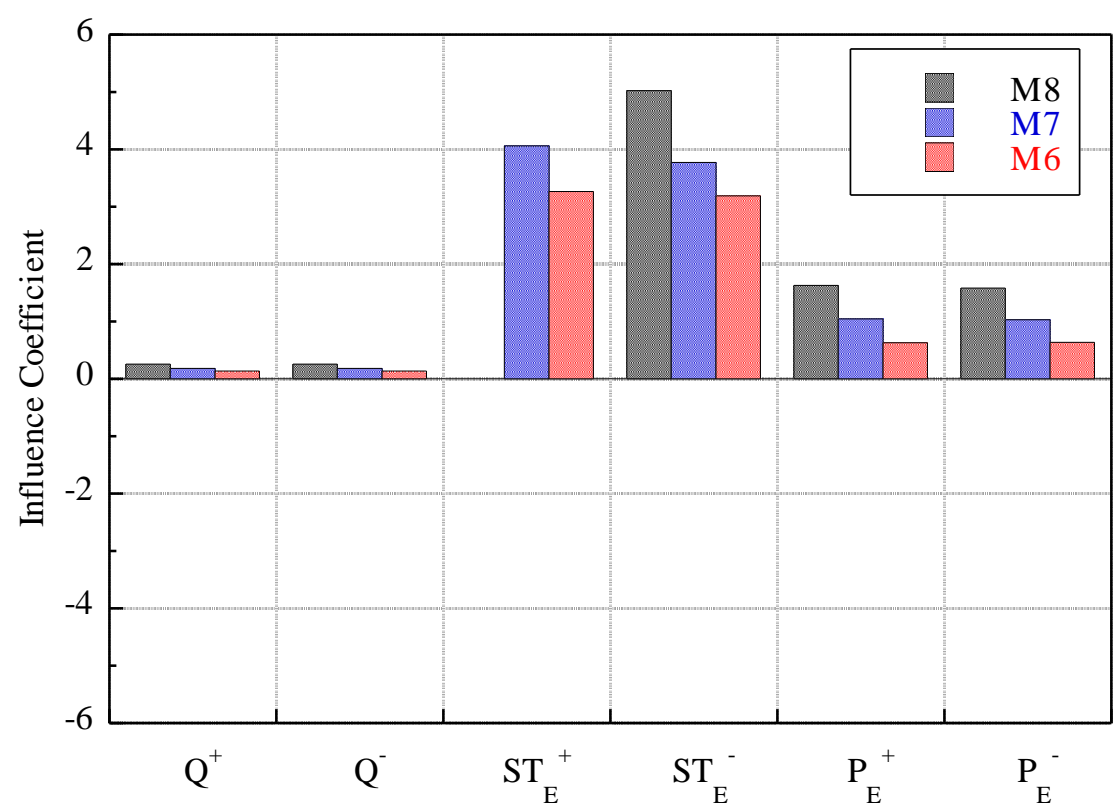

Figure 13. Influence coefficients for performance parameters.

based on a separate sensitivity analysis using Eq. 4.

Figure 14 shows the uncertainty analysis results. The nominal assumptions for parameter-level uncertainties are shown in the plot at the top of each column. Based on these values and the influence coefficients shown in Figure 11 through Figure 13, the range of total uncertainty varies from between $13 \%$ to $20 \%$ of the deduced combustion efficiency as flight conditions change from Mach 6 to Mach 8. It is clear from Figure 14 that fuel enthalpy, combustor exit pressure, and fuel composition make little to no contribution to the total uncertainty in combustion efficiency. Combustor exit geometry, air total temperature, and flowpath heat loss have mild contributions. The three largest contributors are the combustor exit stream thrust, the air mass flow rate, and the fuel flow rate. Therefore, every attempt should be made to incorporate instrumentation and conduct post-test analyses to improve the confidence in these parameters in order to minimize the total uncertainty in combustion efficiency.

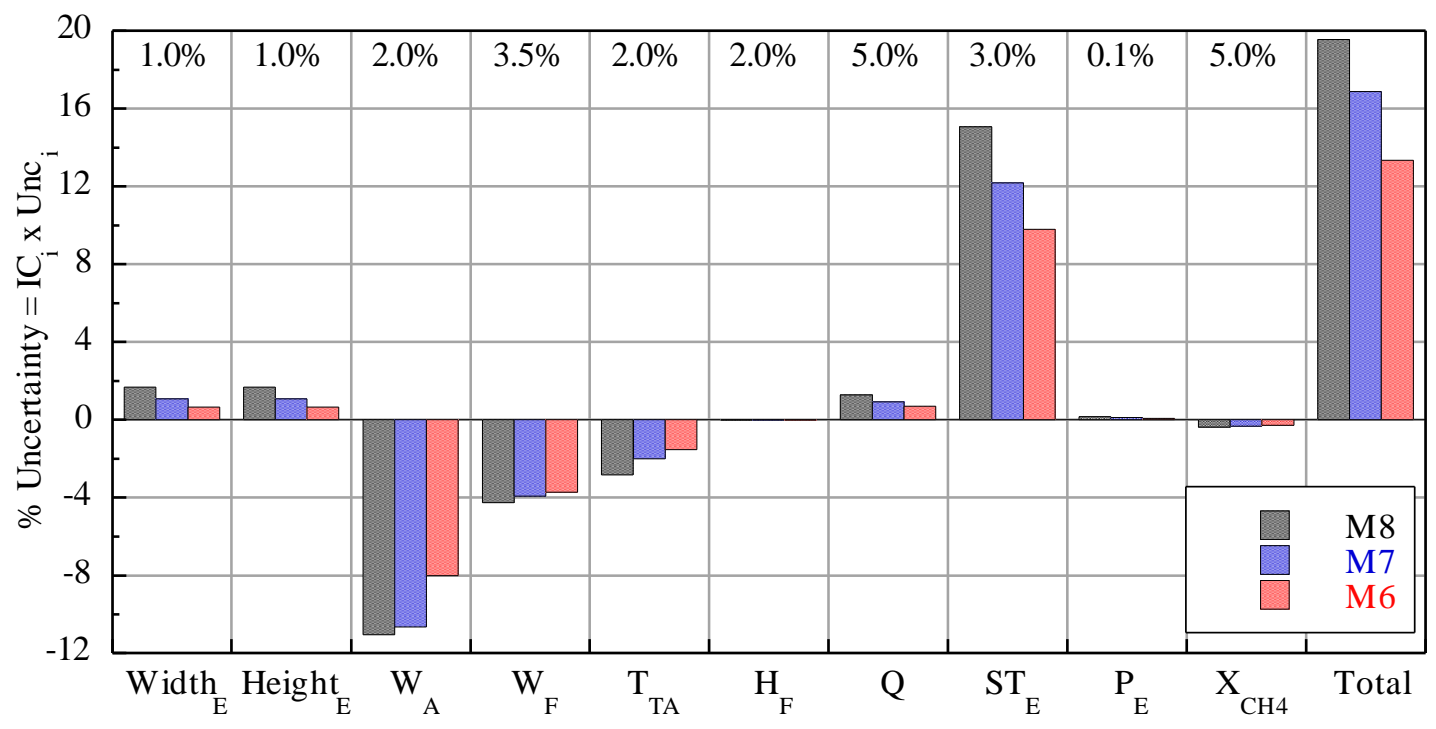

Figure 14. Total uncertainty estimates on deduced combustion efficiency based on nominal component-level uncertainty assumptions. 


\section{Summary}

An approach was described for optimizing the placement of a constrained set of pressure instrumentation in a supersonic combustor flowpath based on the use of CFD solutions. The solutions provided a valuable database for comparing with the wall pressure force determined from several distributions of pressure taps. Results revealed the importance of using instrumentation to capture the three-dimensional pressure field associated with the fuel injection and cavity ramp regions in this flowpath. They also showed that compromises must be made in resolving the wall pressure force over a range of flight conditions because of the significant change in cavity ramp pressure distribution as the combustor operating mode changes from dual-mode to scramjet-mode. Wall pressure force results from the optimized pressure tap distribution showed excellent comparisons with the full CFD solutions from Mach 6, 7, and 8 conditions and were found to be within 3.6\% for all cases and $0.06 \%$ in the Mach 8 case. This level of agreement will help reduce the uncertainty in determining the combustor exit stream thrust.

CFD solutions were also used to examine the validity of a one-dimensional combustor performance analysis tool and to provide input data for use in sensitivity and uncertainty analyses. Results showed good agreement between the CFD-derived and QPERF-derived combustion efficiencies, thereby providing high confidence that the 1D analysis tool will produce reliable performance assessments. Results of the sensitivity and uncertainty analyses revealed that air mass flow rate and combustor exit stream thrust have the largest influence on the determination of combustion efficiency. Fuel enthalpy, fuel composition, and combustor heat loss were found to have relatively small influences. Using nominal uncertainty values assigned to each input parameter, initial estimates of total uncertainty on combustion efficiency were obtained for the range of conditions anticipated in the flight experiment. These values ranged between $13 \%$ and $20 \%$. Opportunities exist to make improvements to these uncertainty values through post-test analysis using on-board instrumentation to improve confidence in the deduced flight conditions.

\section{Acknowledgements}

The authors would like to acknowledge the HIFiRE Program for the opportunity to design and conduct experiments such as those described in this paper. The support of Dr. Thomas Jackson, Mr. Robert Mercier, and Dr. Skip Williams of AFRL/RZA is greatly appreciated.

\section{References}

\footnotetext{
${ }^{1}$ Smart, M. K., Hass, N. E., and Paull, A., "Flight Data Analysis of the HyShot 2 Scramjet Flight Experiment," AIAA Journal, Vol. 44, No. 10, 2006, pp. 2366-2375.

${ }^{2}$ Walker, S. H., Rodgers, F. C., and Esposita, A. L., "Hypersonic Collaborative Australia/United States Experiment (HYCAUSE)," AIAA Paper 2005-3254, May 2005.

${ }^{3}$ Pellett, G. L., Vaden, S. N., and Wilson, L. G., "Gaseous Surrogate Hydrocarbons for a HIFiRE Scramjet that Mimic Opposed Jet Extinction Limits for Cracked JP Fuels," 55th JANNAF Propulsion Meeting, Newton, MA, May 2008.

${ }^{4}$ Jackson, K. R., Gruber, M. R., Jackson, T. A., and Hass, N. E., "HIFiRE Flight 2 Scramjet Flight Experiment Overview," 55th JANNAF Propulsion Meeting, Newton, MA, May 2008.

${ }^{5}$ Ferlemann, P. G., "Forebody and Inlet Design for the HIFiRE 2 Flight Test," 55th JANNAF Propulsion Meeting, Newton, MA, May 2008.

${ }^{6}$ Gruber, M., Jackson, K., Jackson, T., and Liu, J., "Hydrocarbon-Fueled Scramjet Combustor Flowpath Development for Mach 6-8 HIFiRE Flight Experiments," 55th JANNAF Propulsion Meeting, Newton, MA, May 2008.

${ }^{7}$ Donbar, J., Powell, O., Gruber, M., Jackson, K., Jackson, T., Eklund, D., and Mathur, T., "Post-Test Analysis of Flush-Wall Fuel Injection Experiments in a Scramjet Combustor," AIAA Paper 2001-3197, July 2001.

${ }^{8}$ REFPROP v8.0, http://www.nist.gov/srd/nist23.htm, 2009.

${ }^{9}$ Metacomp, http://www.metacomptech.com/index.html, 2005.

${ }^{10}$ Qin, Z., Lissianski, V. V., Yang, H., Gardiner, W. C., Davis, S. G., and Wang, H., "Combustion Chemistry of Propane: A Case Study of Detailed Reaction Mechanism Optimization," Proceedings of the Combustion Institute, Vol. 28, pp. 1663-1669, 2000.

${ }^{11}$ Smith, S., Scheid, A. Eklund, D., Gruber, M., Wilkin, H., and Mathur, T., "Supersonic Combustion Research Laboratory Uncertainty Analysis,” AIAA Paper 2008-5065, July 2008.
}

14

American Institute of Aeronautics and Astronautics 